\title{
Antidiarrhea and Antioxidant Activities of Honokiol Extract from Magnoliae officinalis cortex in Mice
}

\author{
Xuefeng Han ${ }^{1}$, Yuelan Pang ${ }^{2,3}$, Shimin Liư, Zhiliang Tan', Shaoxun Tang ${ }^{1}$, \\ Chuanshe Zhou', Min Wang ${ }^{1}$ and Wenjun Xiao ${ }^{2 *}$ \\ ${ }^{1}$ Key Laboratory of Agro-ecological Processes in Subtropical Region, Institute of Subtropical Agriculture, The Chinese Academy \\ of Sciences, Changsha, Hunan 410125, ${ }^{2}$ National Research Center of Engineering \& Technology for Utilization of Botanical \\ Functional Ingredients, Hunan Agricultural University, Changsha, Hunan 410128, ${ }^{3}$ Tea Science and Research Institute of \\ Guilin. Guangxi, Guilin, Guangxi 541004, China, ${ }^{4}$ School of Animal Biology, University of Western Australia, Crawley, WA 6009 \\ Australia
}

*For correspondence: Email: xiaowenjungong@163.com; Tel: 86-731-84673760; Fax: 86-731-84673760

\begin{abstract}
Purpose: To evaluate the antidiarrhea and antioxidant properties of honokiol extracted from Magnoliae officinalis cortex (bark of Magnolia officinalis), an important medical material in traditional Chinese medicine, for treating diseases such as diarrhea and thrombotic stroke.

Methods: The antidiarrhea activity of honokiol was investigated using castor oil-induced diarrhea as well as neostigmine-induced increase in small intestine transit in mice. In castor oil-induced diarrhoea test, mice received honokiol (25, 50 and $100 \mathrm{mg} / \mathrm{kg} \mathrm{BW}$ ) orally once daily for 1 day and the mice' droppings were observed. In small intestine transit test, mice received honokiol $(25,50$ and $100 \mathrm{mg} / \mathrm{kg}$ BW) orally once daily for 4 days and the percentage distance travelled by charcoal meal was noted to determine. For the determination of anti-oxidant activity, with $50 \mathrm{mg} / \mathrm{kg}$ vitamin $E$ as positive control, the mice were administered with 25,50 or $100 \mathrm{mg} / \mathrm{kg}$ honokiol orally and daily for 14 days. The activity and gene expression of antioxidative enzymes as well as antioxidant status were monitored to assess the antioxidant potential of honokiol.

Results: All doses of honokiol showed $(p<0.001)$ significant inhibitory activity against castor oilinduced diarrhea when compared with model control (diarrhea Index, 1.10 vs. 1.39)-. Honokiol at all doses also reduced neostigmine-stimulated small intestinal transit by approximately $16 \%$ in comparison with -neostigmine control group-(59.0\% vs. 70.1\%). Compared with control (no honokiol), the activities of catalase (CAT), glutathione peroxidase (GSH-PX) and total superoxide dismutase (T-SOD) in the plasma (CAT, 7.31 vs. $13.21 \mathrm{U} / \mathrm{mL}$; GSH-Px, 439.6 vs. $608.9 \mathrm{U} / \mathrm{m} ; \mathrm{T}$-SOD, $82.2 \mathrm{vs.} 109.8 \mathrm{U} / \mathrm{mL}$ ) and liver (CAT, 7.73 vs. 14.39 U/mg; GSH-Px, 167.6 vs. $202.7 \mathrm{U} / \mathrm{mg}$; T-SOD, 44.3 vs. $53.9 \mathrm{U} / \mathrm{mg}$ ) were significantly enhanced by honokiol $(p<0.01)$. CAT and GSH-Px gene expressions were also significantly enhanced by honokiol $(p<0.05)$, compared with control (no honokiol) (CAT, 0.32 vs. 0.39; GSH-Px, 4.49 vs. 5.80). Additionally, total antioxidant capacity was increased by $60 \%$ with $100 \mathrm{mg} / \mathrm{kg}$ honokiol.

Conclusion: The results provide some justification for the use of Magnoliae officinalis cortex as an antidiarrheal remedy in Chinese traditional medicine. The fact that honokiol also enhanced both the non-enzymatic and enzymatic antioxidant defense systems, suggests its potential as a natural antioxidant.
\end{abstract}

Keywords: Magnoliae officinalis cortex, Honokiol, Antidiarrheal, Small intestinal transit, Antioxidant, Gene expression

Tropical Journal of Pharmaceutical Research is indexed by Science Citation Index (SciSearch), Scopus, International Pharmaceutical Abstract, Chemical Abstracts, Embase, Index Copernicus, EBSCO, African Index Medicus, JournalSeek, Journal Citation Reports/Science Edition, Directory of Open Access Journals (DOAJ), African Journal Online, Bioline International, Open-J-Gate and Pharmacy Abstracts 


\section{INTRODUCTION}

In traditional Chinese medicine, Magnoliae officinalis cortex, also known as Houpo, refers to the dried bark of the trunk or root of Magnolia officinalis Rehd. et Wils. or Magnolia officinalis Rehd. et Wils. var. biloba Rehd. et Wils. (Magnoliaceae) [1]. The Magnoliae officinalis cortex has long been used as a popular ingredient in several Chinese traditional remedies for the treatment of diseases, including thrombotic stroke, typhoid fever, diarrhea, anxiety, nervous disturbance and asthma.

Although Magnoliae officinalis cortex has been used as the main ingredient in remedies for the treatment of diarrhea in traditional Chinese medicine, there is no report on the antidiarrhea activity of this plant material per se. Pan et al demonstrated that Huanglian Houpu pill (HLHP) inhibited senna-induced diarrhea in mice [2]. Hu et al also reported that the methanol extract of Wei-Chang-An-Wan (WCAW) protected mice against castor oil-induced diarrhea [3]. WCAW, a typical Chinese herbal preparation, consists of ten herbs, including cortex Magnolia officinalis. Since many traditional Chinese medicines or prescriptions for clinical treatment of diarrhea, including HLHP and WCAW, contain Magnoliae officinalis cortex, it is probable that Magnoliae officinalis cortex plays an important role in the antidiarrheal effect of many traditional medicines; however, the active component(s) and mechanism of action of several of the traditional Chinese antidiarrheal medicines are yet to be elucidated.

Honokiol is a bioactive constituent in Magnoliae officinalis cortex and recent investigations have shown that honokiol possess a wide range of physiological activities, such as antitumor [4], antimicrobial [5], and antiinflammatory activity [6]. Antioxidant activity in vitro of Magnoliae officinalis cortex and honokiol have also been reported $[7,8]$.

We hypothesied that honokiol in Magnoliae officinalis cortex is the primary ingredient involved in both antidiarrheic and antioxidative activity. In this study, therefore, we used a mouse model to investigate the effects of the honokiol extract on castor oil-induced diarrhea, on charcoal transit rate in the small intestines. Furthermore, influence of the honokiol extract on antioxidative enzymes activities and gene expression levels, as well as markers of antioxidant status in plasma and liver of mice were also evaluated.

\section{EXPERIMENTAL}

\section{Animals}

The use of animals and the experimental procedures were approved (ref. no. AWCISA2012012) by the Animal Welfare Committee of the Institute of Subtropical Agriculture, Chinese Academy of Sciences. A total of 140 male Kunming (KM) mice (an outbred mouse stock deriving from Swiss albino mice with a high ratio of gene heterozygosis), 4 - 5 weeks of age, weight $20 \pm 2 \mathrm{~g}$, were obtained from the Hunan SLAC Laboratory Animal Co., Ltd. (Changsha, China). Animals were maintained in standard environmental conditions (ambient temperature: $25 \pm 2{ }^{\circ} \mathrm{C}$, relative humidity: $55-65 \%$ and $12 \mathrm{~h}$ light/dark cycle) and had free access to standard chow diet obtained from Hunan SLAC Laboratory Animal Co., Ltd and distilled water. The animals were acclimatized for one week prior to the commencement of each animal experiment.

\section{Plant material and extract}

The bark of Magnolia officinalis Rehd. et Wils. was collected from Jianghua Yao Autonomous County, Yongzhou City, China in May 2009. The plant species was identified and confirmed by Professor ZH. Liu of Department of Botany Resources, Hunan Agricultural University against the reference preserved at the Specimen Center of Hunan Agricultural University, Changsha, China (Accession No. HNYD-09126).

The bark was dried and ground to pass through a 30 - mesh sieve. This powder was extracted with $60 \%$ ethanol for $2.5 \mathrm{~h}$ at room temperature. The supernatant was concentrated by rotary evaporation at $40{ }^{\circ} \mathrm{C}$ and the residue freezedried. The dried extract was referred to as the crude extract. The purity of honokiol in the crude extract was $89.3 \%$, as measured by high performance liquid chromatography (HPLC).

The crude extract was reconstituted in $60 \%$ ethanol and further purified with HP-20 macroporous absorbing resin. The eluent containing honokiol was collected by fraction collector. The solvent was removed by rotary evaportion at $-0.05 \mathrm{MPa}$ at $70{ }^{\circ} \mathrm{C}$ and the residue freeze-dried. This procedure increased the purity to $91.3 \%$ by HPLC. The extracted honokiol was dissolved in $2 \%$ aqueous Tween 80 solution (V/V) immediately prior to oral administration to the mice.

\section{Drugs/chemicals}


Castor oil was obtained from Tianjin Fuchen Chemicals Reagent Factory (B.N. 20070704). Loperamide hydrochloride, a medicine for treatment of diarrhea, was provided by XianJanssen Pharmaceutical Ltd (B.N. 09041541). Neostigmine was obtained from Shandong Tianfu Pharmaceutical Ltd (batch no. 080701). Glutathione peroxidase (GSH-Px), total superoxide dismutase (T-SOD), catalase (CAT), glutathione (GSH) and total antioxidant capacity (T-AOC) assay kits were purchased from Nanjing Jiancheng Bioengineering Institute (Nanjing, China). Power SYBR Green PCR Master Mix was obtained from Applied Biosystems (CA, USA).

\section{Test for antidiarrhea activity}

\section{Castor oil-induced diarrhea}

A diarrhea model in mice was established by single oral administration (by gavage) of castor oil at dose of $20 \mathrm{ml} / \mathrm{kg}$ body weight (BW) [9]. Sixty mice were fasted for $24 \mathrm{~h}$ and randomly allocated into six equal groups based on BW. Both control group and model control group orally received saline $(0.9 \%$ W/V sodium chloride) $(20 \mathrm{ml} / \mathrm{kg} \mathrm{BW})$. The positive control group was orally administered with loperamide hydrochloride (Xian-Janssen Pharmaceutical, Ltd. B.N. 09041541) $3 \mathrm{mg} / \mathrm{kg}$ BW according to the medicine package insert. The remaining three groups were orally administered by gavage with the honokiol extract solution at doses of 25 (Honokiol 25), 50 (Honokiol 50) or 100 (Honokiol 100) $\mathrm{mg}$ honokiol/kg BW respectively at the same volume. The dose setting of honokiol in this study referred to results of Hsieh et al [10], Atanasov et al [11] and Pang et al [12].

Then 30 min after treatment, all mice, except for the control, were orally administered with castor oil. The control mice received an equivalent oral volume of saline. Then animals were placed in individual cages, the floor of which was covered with filter paper that was replaced hourly. The numbers and morphology of the stools were recorded for $6 \mathrm{~h}$ after the administration of castor oil. The total number of stools over the $6 \mathrm{~h}$ was determined. The severity of diarrhea was defined using three indices: loose stool incidence rate (LSIR), average loose stool grade (ALSG) and diarrhea index (DI) [13]. LSIR is the ratio of number of loose stools to the total stools within an animal. Loose stool grade (LSG) describes the degree of loose stools, based on the diameter of the stool on the filter papers. LSG was classified into four grades according the diameter of loose stools: Grade $1(<1 \mathrm{~cm})$, Grade $2(1 \sim 1.9 \mathrm{~cm})$, Grade $3(2 \sim 3 \mathrm{~cm})$, and
Grade 4 (>3 cm). ALSG is the ratio of the sum of LSG of each loose stool to the total number of loose stools within an animal. DI is the result of LSR multiplying ALSG.[13]

\section{Effect on charcoal transit in the small intestines}

The effect of honokiol on gastrointestinal motility was tested by measuring charcoal transit in the small intestines of the mice [14]. Healthy Kunming mice were randomly divided into five groups based on BW with ten mice per group. The 5 groups were control (saline throughout), neostigmine (saline plus neostigmine treatment) and three honokiol groups (honokiol plus neostigmine treatment). The 3 honokiol groups were orally administered by gavage with the honokiol extract solution at $20 \mathrm{ml} / \mathrm{kg} \mathrm{BW}$ to supply doses of 25 (Honokiol 25), 50 (Honokiol 50 ) or 100 (Honokiol 100) $\mathrm{mg} / \mathrm{kg}$ BW, respectively. The control and neostigmine groups were both administered with saline at dose of 20 $\mathrm{ml} / \mathrm{kg}$ BW. Honokiol and saline were administered once per day for 4 days. On day 4 , all mice, except for control group, were administered with neostigmine $(0.15 \mathrm{mg} / \mathrm{kg}$ BW by intraperitoneal injection according to the medicine package insert) $30 \mathrm{~min}$ after the oral administration of honokiol or saline. Then $20 \mathrm{~min}$ later, all mice, including those in normal control group, were orally administered with charcoal meal (5\% (W/V) charcoal suspension in a $1 \%$ (W/V) carboxy methyl cellulose solution) at dose of $10 \mathrm{ml} / \mathrm{kg} \mathrm{BW}$ [15]. Then $20 \mathrm{~min}$ after the charcoal meal, all animals were sacrificed by cervical dislocation. The small intestine was removed immediately and total length measured. The distance $(\mathrm{cm})$ that the charcoal meal had travelled from the pylorus into the intestinal lumen was measured, and small intestinal transit (SIT) of the charcoal was expressed as the percentage of the longest distance travelled by the charcoal divided by the length of the small intestine [16].

\section{Test for antioxidative activity}

\section{Animals and treatment}

Forty male Kunming mice were randomly divided into five equal groups: the control group orally received $2 \%$ aqueous Tween 80 solution; the positive control group orally received $50 \mathrm{mg} / \mathrm{kg}$ BW vitamin $E$ dissolved in $2 \%$ aqueous Tween 80 solution [17]; the three honokiol-treatment groups orally received the honokiol extract at doses of 25,50 or $100 \mathrm{mg} / \mathrm{kg}$ BW respectively. The solvent, vitamin $E$ and the honokiol extract were orally administered once per day for 14 
days [18]. All dose volumes were the same. On the morning of day 15 of the treatment, all mice were anesthetized with ether. Blood sample (about 0.2 to $0.3 \mathrm{ml}$ per mouse) was collected via retro-orbital bleeding into heparinized tubes prior to cervical dislocation. Plasma was separated by centrifuging at $1200 \mathrm{~g}$ for $10 \mathrm{~min}$ and stored at $20{ }^{\circ} \mathrm{C}$ until analysis of activity of antioxidative enzymes. Then the liver was rapidly removed under aseptic condition, washed in cold saline, chopped and frozen in liquid nitrogen. The liver sample was stored at $-70{ }^{\circ} \mathrm{C}$ until further analysis.

\section{Chemical analysis}

The activities of glutathione peroxidase (GSH$\mathrm{Px}$ ), total superoxide dismutase (T-SOD) and catalase (CAT) in both the plasma and liver, and glutathione (GSH) concentration and total antioxidant capacity (T-AOC) in the liver were measured using commercial available kits (Nanjing Jiancheng Bioengineering Institute).To analyse the liver sample, the sample was homogenized in 9 volumes of ice-cold saline. The homogenate was then centrifuged at $1200 \mathrm{~g}$ at $4{ }^{\circ} \mathrm{C}$ for $10 \mathrm{~min}$. The supernatant was used for all assays performed according to the manufacturer's instructions. The CAT activity was determined spectrophotometrically using the method of Goth [19]. The SOD activity was measured spectrophotometrically according to the method of Flohé and Otting [20]. The GSHPx activity was determined using the method described by Lawrence and Burk [21]. The GSH concentration was measured spectrophotometrically with the procedures described by Sedlak and Lindsay [22]. The TAOC was measured based on the method of Benzie and Strain [23].

\section{Gene expression analysis}

The expression of CAT, GSH-Px, copper-zinc SOD (Cu/Zn-SOD), manganese SOD (Mn-SOD), and extracellular SOD (EC-SOD) at RNA levels in the liver were determined by using quantitative real-time PCR (qPCR). qPCR was performed on the ABI $7900 \mathrm{HT}$ fast real-time PCR system (Applied Biosystems, CA, USA) and the qPCR primers of Pang et al were used [12].

The qPCR reactions were conducted in triplicate using a $10 \mu \mathrm{L}$ reaction mixture containing $5 \mu \mathrm{L} 2$ $\times$ Power SYBR Green PCR Master Mix, $0.1 \mu \mathrm{L}$ cNDA template, $0.3 \mu \mathrm{L}$ forward primer (1 $\mu \mathrm{mol} / \mathrm{L}), 0.3 \mu \mathrm{L}$ reverse primer $(1 \mu \mathrm{mol} / \mathrm{L})$ and 4.3 $\mu \mathrm{L}$ DEPC-treated distilled water. The qPCR cycling conditions were as follows: $95^{\circ} \mathrm{C}$ held at $10 \mathrm{~s}$ and 40 cycles of $95^{\circ} \mathrm{C}$ for $20 \mathrm{~s}, 60^{\circ} \mathrm{C}$ for 30 s. The relative changes of mRNA expression determined from qPCR were calculated according to the $2 \Delta \mathrm{Ct}$ method, where, $\Delta \mathrm{Ct}=\mathrm{Ct}$ samples - Ct $\beta$-actin and the $\mathrm{Ct}$ (threshold cycle) value denotes the number of PCR cycles required for the sample fluorescence to reach the threshold level.

\section{Statistical analysis}

The data were analyzed by using ANOVA procedures, followed by Dunnett's comparisons test using SAS software (version 8, SAS Institute, Cary, NC, USA). The least square means $\pm S D$ of the data are presented. Differences between the honokiol extract treatment and controls were considered at $p<$ 0.05 .

\section{RESULTS}

\section{Inhibition of honokiol on castor oil-induced diarrhea}

ALSG did not differ between model control, positive control and honokiol treatment groups (Table 1). When compared with the model group, the honokiol treatments had lower LSR and DI values $(p<0.001)$; whereas the values were higher in comparison with the positive control ( $p$ $<0.001$ ). No differences in LRS and DI were found between the three honokiol groups.

\section{Effect of honokiol on small intestinal transit (SIT)}

There were no differences in the small intestine length between groups (Table 2). When compared with the control group, the honokiol treatments did not change the distance travelled by charcoal, but increased SIT $(p<0.01)$. In comparison with the neostigmine group, the SIT values for the honokiol groups were lower $(p<$ $0.01)$. Neostigmine treatment produced greatest $(p<0.01)$ distance travelled by charcoal and high SIT when compared with the control. Between the three honokiol groups there were no differences either in the charcoal distance travelled or the SIT.

\section{Effect of honokiol on the activity of antioxidant enzymes in plasma}

The impact of honokiol on antioxidant enzymes in plasma are shown in Figure 1. The activities $(\mathrm{U} / \mathrm{mL})$ of CAT, GSH-Px and T-SOD in the three honokiol groups were higher $(p<0.01)$ than those in the control group. There were no differences in the activities of CAT, GSH-Px and 
T-SOD between honokiol groups and the vitamin $\mathrm{E}$ treated control. No differences were observed in the activity of the three antioxidant enzymes between the honokiol groups.

\section{Effect of honokiol on antioxidant status in mouse liver}

When compared with the control group, the activities of CAT, GSH-Px and T-SOD in the three honokiol groups were greater $(p<0.01)$, T-
AOC was higher only in the Honokiol 100 group $(p<0.001)$, but GSH concentration were similar (Table 3). Compared with the positive control, CAT activities were higher in Honokiol 50 and 100 groups $(p<0.05)$ and T-AOC was greater for the Honokiol 100 group only $(p<0.05)$. In addition, T-AOC of Honokiol 100 was greater ( $p$ $<0.01$ ) than those of Honokiol 25 and 50, but GSH concentration and activities of CAT, T-SOD, and GSH-Px were similar for all three honokiol groups.

Table 1: Effects of honokiol on prevention of diarrhea induced by castor oil in mice $(n=10)$

\begin{tabular}{lccc}
\hline Group & Loose stool rate (LSR) & Mean loose stool grade (ALSG) & Diarrhea Index(DI) \\
\hline Control & 0 & 0 & 0 \\
Model control & $0.83 \pm 0.09$ & $1.67 \pm 0.13$ & $1.38 \pm 0.16$ \\
Positive control & $0.37 \pm 0.08$ & $1.67 \pm 0.12$ & $0.62 \pm 0.15$ \\
Honokiol 25 & $0.71 \pm 0.11^{\mathrm{A}, \mathrm{c}}$ & $1.55 \pm 0.15$ & $1.10 \pm 0.20^{\mathrm{b}, \mathrm{C}}$ \\
Honokiol 50 & $0.67 \pm 0.09^{\mathrm{b}, \mathrm{C}}$ & $1.63 \pm 0.16$ & $1.11 \pm 0.21^{\mathrm{b}, \mathrm{C}}$ \\
Honokiol 100 & $0.66 \pm 0.09^{\mathrm{c}, \mathrm{C}}$ & $1.66 \pm 0.18$ & $1.08 \pm 0.16^{\mathrm{b}, \mathrm{C}}$ \\
\hline
\end{tabular}

Control: saline only; Model control: saline + castor oil; Positive control: loperamine hydrochloride + castor oil; ${ }^{a} p<$ $0.05,{ }^{b} p<0.01,{ }^{c} p<0.001$, when the values of honokiol-treated groups are compared with model control group; ${ }^{A} p<0.05,{ }^{B} p<0.01,{ }^{C} p<0.001$, when compared with positive control group

Table 2: Effect of honokiol on charcoal transit in the small intestine of mice $(n=10)$

\begin{tabular}{lccc}
\hline Group & $\begin{array}{c}\text { Small intestine length } \\
(\mathbf{c m})\end{array}$ & $\begin{array}{c}\text { Distance travelled by charcoal } \\
(\mathbf{c m})\end{array}$ & $\begin{array}{c}\text { Small intestinal transit } \\
(\%)\end{array}$ \\
\hline Control & $51.8 \pm 5.65$ & $24.9 \pm 5.11$ & $47.9 \pm 7.41$ \\
Neostigmine & $52.3 \pm 4.08$ & $36.6 \pm 4.25$ & $70.1 \pm 6.89$ \\
Honokiol 25 & $48.3 \pm 3.97$ & $28.3 \pm 3.83^{\mathrm{C}}$ & $58.7 \pm 7.32^{\mathrm{b}, \mathrm{B}}$ \\
Honokiol 50 & $49.2 \pm 3.49$ & $29.0 \pm 4.37^{\mathrm{B}}$ & $59.0 \pm 8.76^{\mathrm{b}, \mathrm{B}}$ \\
Honokiol 100 & $50.7 \pm 3.34$ & $30.0 \pm 3.06^{\mathrm{B}}$ & $59.2 \pm 4.80^{\mathrm{bB}}$ \\
\hline
\end{tabular}

${ }^{a} p<0.05,{ }^{b} p<0.01,{ }^{c} p<0.001$, when the values of honokiol-treated groups are compared with control (saline only) group; ${ }^{A} p<0.05,{ }^{B} p<0.01,{ }^{C} p<0.001$, when compared with the neostigmine group

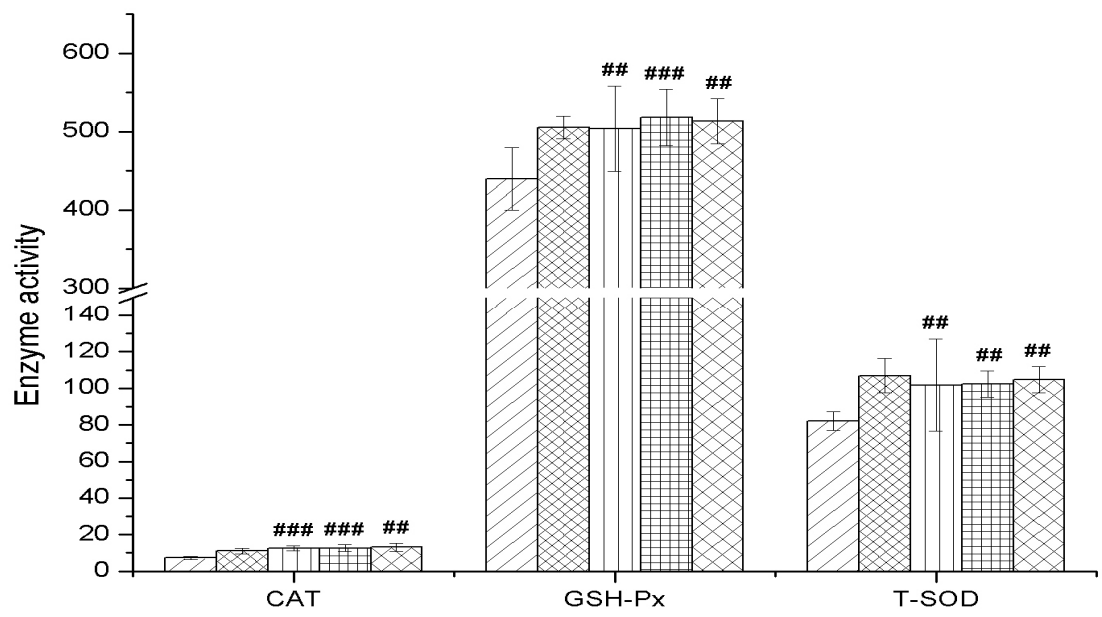

Fig 1: Effects of honokiol on activity of antioxidation enzymes in plasma of mice $(\mathrm{n}=8)$. The unit of enzyme activity is U/mL; Control: Tween 80 solution only; Positive control: Vitamin E (50 mg/kg BW); ${ }^{\#} P<0.05$, ${ }^{\# \#} P<$ $0.01,{ }^{\# \#} P<0.001$, compared with control group; ///: Control; $\ldots$ : Positive control; III: Honokiol 25; \#冊: Honokiol 50; XXX: Honokiol 100 
Effects of honokiol on mRNA abundance of antioxidant enzymes in the liver

When compared with the control, the gene expression of CAT was greater for the Honokiol 100 group only $(p<0.05)$; the gene expression of GSH-Px was greater in Honokiol 50 and 100 groups $(p<0.05)$, but no differences were found in the gene expressions of $\mathrm{Cu} / \mathrm{Zn}-\mathrm{SOD}, \mathrm{Mn}-\mathrm{SOD}$ and EC-SOD (Table 4). When compared with the positive control, the gene expression of CAT was lower in the Honokiol 50 group $(p<0.05)$, the gene expression of GSH-Px was lower in the Honokiol 25 and 50 groups $(p<0.01)$, but there was no difference in the mRNA abundance for $\mathrm{Cu} / \mathrm{Zn}-\mathrm{SOD}, \mathrm{Mn}-\mathrm{SOD}$ and EC-SOD in the honokiol-treated groups. Honokiol 100 mice had the greatest mRNA abundance for CAT and GSH-Px among the three honokiol groups. Furthermore, CAT gene expression in the Honokiol 50 was lower $(p<0.001)$ than that for Honokiol 100, while GSH-Px expression of the Honokiol 25 group was also lower $(p<0.001)$ than that for Honokiol 100.

\section{DISCUSSION}

Honokiol is one of two major groups of bioactive compounds isolated from the cortex of Magnolia officinalis. The current study shows, for the first time, that the honokiol extracted from cortex Magnolia officinalis reduces the severity of diarrhea induced by castor oil, as indicated by the reduction of the loose stool rate and diarrhea index in mice.

Castor oil causes diarrhea in animals due to the action of its active metabolite, ricinoleic acid, derived from hydrolysis of its triglyceride in the duodenum by pancreatic lipase. The released ricinoleic acid causes irritation and inflammation of the intestinal mucosa and also stimulates intestinal hypermotility and hypersecretion. These series of actions lead to diarrhea $[24,25]$. Since the honokiol extract successfully reduced severity of diarrhea induced by castor oil in this study, honokiol may therefore exert its antidiarrhea actions via antiinflammatory, antihypermotility or anti-hypersecretion activities

In this study honokiol showed anti-hypermotility actions as evident from the inhibition of the increased intestinal transit induced by neostigmine (a medicine for improving smooth muscle tone), which showed that honokiol has intestinal smooth muscle relaxation quality. Honokiol has been reported to relax smooth muscle in the porcine trachea [26]. Honokiol also inhibits the contractility of isolated gastric fundus strips of rats and the isolated ileum of guinea pigs, through a mechanism thought to be associated with a calcium-antagonistic effect [27]. The retardation of hyperactive intestinal

Table 3: Effect of honokiol on antioxidant status in the liver of mice $(n=8)$

\begin{tabular}{lccccc}
\hline Group & $\begin{array}{c}\text { CAT } \\
(\mathbf{U} / \mathbf{m g})\end{array}$ & $\begin{array}{c}\text { T-SOD } \\
\mathbf{( U / m g )}\end{array}$ & $\begin{array}{c}\text { GSH-Px } \\
(\mathbf{U} / \mathbf{m g})\end{array}$ & $\begin{array}{c}\text { GSH } \\
(\mathbf{m g} / \mathbf{m g})\end{array}$ & $\begin{array}{c}\text { T-AOC } \\
(\mathbf{U} / \mathbf{m g})\end{array}$ \\
\hline Control & $7.73 \pm 1.31$ & $44.3 \pm 4.77$ & $167.6 \pm 13.06$ & $0.79 \pm 0.07$ & $0.60 \pm 0.09$ \\
Positive control & $10.19 \pm 1.25$ & $56.9 \pm 4.97$ & $201.3 \pm 14.84$ & $0.89 \pm 0.09$ & $0.72 \pm 0.08$ \\
Honokiol 25 & $12.92 \pm 3.43^{\mathrm{b}}$ & $54.0 \pm 3.84^{\mathrm{C}}$ & $200.2 \pm 8.69^{\mathrm{C}}$ & $0.81 \pm 0.07$ & $0.71 \pm 0.13$ \\
Honokiol 50 & $14.47 \pm 3.01^{\mathrm{C}, \mathrm{A}}$ & $53.8 \pm 3.70^{\mathrm{C}}$ & $204.4 \pm 9.03^{\mathrm{c}}$ & $0.84 \pm 0.09$ & $0.71 \pm 0.10$ \\
Honokiol 100 & $15.79 \pm 2.04^{\mathrm{C}, \mathrm{B}}$ & $54.0 \pm 5.12^{\mathrm{C}}$ & $203.4 \pm 29.13^{\mathrm{C}}$ & $0.90 \pm 0.07$ & $0.96 \pm 0.23^{\mathrm{C}, \mathrm{A}}$ \\
\hline
\end{tabular}

The values are expressed as per mg protein in the liver; ${ }^{a} p<0.05,{ }^{b} p<0.01,{ }^{c} p<0.001$, when the values of honokiol-treated groups are compared with control (Tween 80 solution only) group; ${ }^{A} p<0.05,{ }^{B} p<0.01,{ }^{C} p<$ 0.001 , when compared with positive control (vitamin E) group

Table 4: Effect of honokiol on mRNA abundance of antioxidant enzymes in the liver of mice $(n=5)$

\begin{tabular}{|c|c|c|c|c|c|}
\hline Group & CAT & GSH-Px & Cu/Zn-SOD & Mn-SOD & EC-SOD \\
\hline Control & $0.32 \pm 0.02$ & $4.49 \pm 0.69$ & $1.28 \pm 0.19$ & $0.060 \pm 0.015$ & $0.002 \pm 0.0011$ \\
\hline Positive control & $0.42 \pm 0.06$ & $7.08 \pm 0.56$ & $1.55 \pm 0.14$ & $0.074 \pm 0.018$ & $0.002 \pm 0.0010$ \\
\hline Honokiol 25 & $0.41 \pm 0.08$ & $4.89 \pm 0.62^{C}$ & $1.37 \pm 0.21$ & $0.061 \pm 0.013$ & $0.003 \pm 0.0003$ \\
\hline Honokiol 50 & $0.29 \pm 0.07^{\mathrm{A}}$ & $5.73 \pm 0.68^{\mathrm{a}, \mathrm{B}}$ & $1.54 \pm 0.17$ & $0.071 \pm 0.018$ & $0.002 \pm 0.0007$ \\
\hline Honokiol 100 & $0.48 \pm 0.09^{b}$ & $6.77 \pm 0.59^{c}$ & $1.60 \pm 0.12$ & $0.081 \pm 0.014$ & $0.003 \pm 0.0019$ \\
\hline
\end{tabular}


An alternative mechanism for honokiol action might be as a $\mathrm{Ca}^{2+}$ transport antagonist. Lu et al reported that honokiol inhibited uterine contraction in rats by blocking external $\mathrm{Ca}^{2+}$ influx [28]. The relaxant effect of honokiol on the tracheal smooth muscle of pig also involved blockade of $\mathrm{Ca}^{2+}$ influx through voltage-operated $\mathrm{Ca}^{2+}$ channels instead of $\mathrm{Ca}^{2+}$ release from intracellular $\mathrm{Ca}^{2+}$ stores [26]. Consequently, honokiol may be considered a putative calcium antagonist or calcium channel blocker. Calcium is involved in secretory diarrhea by modulating secretion of chloride or potassium, and gut motility also appears mediated by calcium flux $[29,30]$. As a calcium antagonist, honokiol may have both antimotility and antisecretory effects, both of which might help alleviate diarrhea.

Taken as a whole, the antidiarrheal activity of honokiol may involve integration of multiple mechanisms, among which, the retardation of small intestinal transit and $\mathrm{Ca}^{2+}$-channel block may be included. The exact mechanism will require further investigation. The current studies indicate that honokiol exerts significant antidiarrheal and antimotility activity. Furthermore, our previous studies have also showed that magnolol has both antidiarrheal and antimotility effects [12]. Honokiol and magnolol are two biphenolic compounds. The contents of honokiol and magnolol in cortex Magnoliae officinalis contex were $1.2 \%$ and $0.9 \%$, respectively [31]. Honokiol and magnolol are commonly seen as two major bioactive constituents of Magnoliae officinalis cortex. The antidiarrheal and antimotility functions of honokiol and magnolol could possibly explain the reason for Magnoliae officinalis cortex being contained in many traditional Chinese medicines or prescriptions for treating diarrhea. The results in this study may provide reference to prepare some Chinese patent drugs or herbal extract medicines of Magnoliae officinalis cortex to treat diarrhea.

The Magnoliae officinalis cortex has been found to have antioxidant properties in vitro [7]. In this study, CAT, GSH-Px and SOD activities in both plasma and liver of mice were all increased by the honokiol extract. These changes were accompanied by elevated mRNA abundance for CAT and GSH-Px, and the expression levels of CuZn-SOD, Mn-SOD and EC-SOD genes in the honokiol extract-treated mice were numerically higher than that in control mice. Therefore, an administration of the honokiol extract to mice induced the increment in CAT, GSH-Px and TSOD activities possibly by up-regulating the expression of genes of antioxidant enzymes.
GSH in tissues plays a central role in the antioxidant defense system through direct detoxification ROS or via a GSH-Px catalyzed mechanism. The physiological role of GSH is as an essential intracellular reducing agent for the maintenance of reducing state of thiol groups and other antioxidant molecules. The results of the present study demonstrated that the honokiol extract tended to increase GSH concentration in the liver of mice, in a linear dose-dependent manner $\left(p<0.01, \mathrm{R}^{2}=0.981\right)$. Honokiol has been found to have a protective effect against $D$ galactosamine-induced hepatotoxicity, which is used as an alternate model to oxidative stress, acting by inhibiting intracellular GSH depletion [32].

Total antioxidant capacity (T-AOC) reflects the capacity of the non-enzymatic antioxidant defense system. Only at the highest dose of honokiol extract, was T-AOC increased for the liver. The results showed that the honokiol extract at appropriate dose increased the activities of both the non-enzymatic and enzymatic anti-oxidant defense systems and has potential for use as a natural antioxidant.

\section{CONCLUSION}

The findings of this demonstrate that honokiol extract possesses antidiarrheal activities, which likely contribute to the antidiarrheal efffect of Magnolia officinalis cortex in Chinese traditional medicine. The enhancement effects of honokiol extract on both the non-enzymatic and enzymatic anti-oxidant defense systems required to unravel its mechanisms of action.

\section{ACKNOWLEDGEMENT}

The advice of $\mathrm{Dr}$ Gerald Lobley (University of Aberdeen, United Kingdom) in manuscript revision is appreciated. The authors express their sincere gratitude to the National Natural Science Foundation of China (Grant no. 30972166), Hunan Provincial Education Department (Grant no. 08A031) and Ministry of Science and Technology (Grant no. 2007DFA31360) for financial support for this study.

The first two named authors contributed equally to this work and should be regarded as co-first authors. 


\section{REFERENCES}

1. Committee of National Pharmacopoeia of PR China. Pharmacopoeia of People's Republic of China. Vol. 1. Beijing: Press of Chemical Industry 2010; pp 235.

2. Pan HG, Li RL, Li WM, Xu SF, Ye FQ, Chen WW. Effects of Huanglian Houpu pill on the acute gastric mucosal damage, diarrhea and vomiting models in animals. Chin J New Drugs 2004; 13: 126-128.

3. Hu J, Gao WY, Ling NS, Liu CX. Antidiarrhoeal and intestinal modulatory activities of Wei-Chang-An-Wan extract. J Ethnopharmacol 2009; 125: 450-455.

4. Han $L L$, Xie $L P$, Li LH, Zhang XW,Zhang RQ, Wang $H Z$. Reactive oxygen species production and $\mathrm{Bax} / \mathrm{Bcl}-2$ regulation in honokiol-induced apoptosis in human hepatocellular carcinoma SMMC-7721 cells. Environ Toxicol Pharmaco 2009; 28: 97-103.

5. Ho KY, Tsai CC, Chen CP, Huang JS, Lin CC. Antimicrobial activity of honokiol and magnolol isolated from Magnolia officinalis. Phytother Res 2001; 15: 139-141.

6. Park J, Lee J, Jung E, Park Y, Kim K, Park B, Jung K, Park E, Kim J, Park D. In vitro antibacterial and antiinflammatory effects of honokiol and magnolol against propionibacterium sp. Eur J Pharmacol 2004; 496: 189-195.

7. Chan LW, Cheah EL, Saw CL, Weng W, Heng PW. Antimicrobial and antioxidant activities of cortex Magnoliae officinalis and some other medicinal plants commonly used in South-East Asia. Chinese Med 2008; 3: 15.

8. Dikalov S, Losik T, Arbiser JL. Honokiol is a potent scavenger of superoxide and peroxyl radicals. Biochem Pharmacol 2008; 76: 589-596.

9. Islam M, Barua J, Karon B, Noor M. Antimicrobial, cytotoxic and antidiarrhoeal activity of Fimbristylis aphylla L. Int J Green Pharm 2011; 5: 135-137.

10. Hsieh MT, Chueh FY, Lin MT. Magnolol decreases body temperature by reducing 5-hydroxytryptamine release in the rat hypothalamus. Clin Exp Pharmacol Physiol 1998; 25: 813-817.

11. Atanasov AG, Wang JN, Gu SP, Bu J, Kramer MP, Baumgartner L, Fakhrudin N, Ladurner A, Malainer C, Vuorinen A, Noha SM, Schwaiger S, Rollinger JM, Schuster D, Stuppner H, Dirsch VM, Heiss EH. Honokiol: a non-adipogenic PPARY agonist from nature. Biochim Biophys Acta 2013; 1830: 48134819.

12. Pang YL, Han XF, Bamikole MA, Gong ZH, Tang SX, Tan ZL, Xiao WJ. Zhou CS, Wang M, Deng YL. Antidiarrhea and anti-oxidant properties of Magnolol. Trop J Pharm Res 2013; 12: 85-91.

13. Zhou GN, Hu ZH, Wang $Y X$, Zhang KB. An inquiry into preparing diarrhea model of mice and application of diarrhea index. Chin Tradit Herbal Drugs 1994; 25: 195-196.

14. Suleiman MM, Dzenda T, Sani CA. Antidiarrhoeal activity of the methanol stem-bark extract of Annona senegalensis Pers. (Annonaceae). J Ethnopharmacol 2008; 116: 125-130.

15. Hossain MS, Alam MB, Asadujjaman M, Zahan R, Islam MM, Mazumder ME, Haque ME. Antidiarrheal, Antioxidant and Antimicrobial Activities of the Musa sapientum Seed. Avicenna J Med Biotechnol 2011; 3: 95-105.

16. Peddyreddy MK, Dkhar SA, Ramaswamy S, Naveen AT, Shewade DG. An inherent acceleratory effect of insulin on small intestinal transit and its pharmacological characterization in normal mice. World J Gastroenterol 2006; 12: 2593-2600.

17. Rai S, Wahile A, Mukherjee K, Saha BP, Mukherjee PK. Antioxidant activity of Nelumbo nucifera (sacred lotus) seeds. J Ethnopharmacol 2006; 104: 322-327.

18. El-Shenawy NS, Al-Eisa RA, El-Salmy F, Salah O. Prophylactic effect of vitamin $E$ against hepatotoxicity, nephrotoxicity, haematological indices and histopathology induced by diazinon insecticide in mice. Curr Zool 2009; 55: 219-226.

19. Goth L. A simple method for determination of serum catalase activity and revision of reference range. Clin Chim Acta 1991; 196: 143-151.

20. Flohé L, Otting F. Superoxide dismutase assay. Methods Enzymol 1984; 195: 93-104.

21. Lawrence RA, Burk RF. Glutathione peroxidase activity in selenium-deficient rat liver. Biochem. Biophys Res Commun 1976; 71: 952-958.

22. Sedlak J, Lindsay RHC. Estimation of total, protein bound and non-protein sulfhydryl groups in tissue with Ellmann's reagent. Anal Biochem 1968; 25: 192-205.

23. Benzie IF, Strain JJ. The ferric reducing ability of plasma (FRAP) as a measure of "antioxidant power": the FRAP assay. Anal Biochem 1996; 239: 70-76.

24. Iwao I, Terada Y. On the mechanism of diarrhea due to castor oil. Jpn J Pharmacol 1962; 12: 137-145.

25. Ammon PJ, Thomas, Philips S. Effects of oleic and recinoleic acids net jejunal water and electrolyte movement. J Clin Invest 1974; 53: 374-379.

26. $\mathrm{Ko} \mathrm{CH}$, Chen $\mathrm{HH}$, Lin YR, Chan MH. Inhibition of smooth muscle contraction by magnolol and honokiol in porcine trachea. Planta Med 2003; 69: 532-536.

27. Zhang WW, Li Y, Wang XQ, Tian F, Cao H, Wang MW, Sun QS. Effects of magnolol and honokiol derived from traditional Chinese herbal remedies on gastrointestinal movement. World J Gastroenterol 2005; 11: 4414-4418.

28. Lu YC, Chen HH, Ko CH, Lin YR, Chan MH. The mechanism of honokiol-induced and magnololinduced inhibition on muscle contraction and $\mathrm{Ca} 2+$ mobilization in rat uterus. Naunyn. Schmiedebergs. Arch Pharmacol 2003; 368: 262-269.

29. Irie K, Yoshioka T, Nakai A, Ochiai K, Nishikori T, Wu GR, Shibuya H, Muraki T. A Ca(2+) channel blockerlike effect of dehydrocurdione on rodent intestinal and vascular smooth muscle. Eur J Pharmacol 2000; 403: 235-242.

Trop J Pharm Res, October 2014; 13(10): 1650 
Han et al

30. Hodges $K$, Gill R. Infectious diarrhea: Cellular and molecular mechanisms. Gut Microbes 2010; 1: 4-21.

31. Li Y, Long H, Liu HW. Determination of Magnolol and Honokiol in Cortex Magnoliae Officinalis by Capillary Zone Electrophoresis. J Chin Pharmaceut Sci 2000; 9: $80-83$.
32. Park EJ, Zhao YZ, Na M, Bae K, Kim YH, Lee BH, Sohn $\mathrm{DH}$. Protective effects of honokiol and magnolol on tertiary butyl hydroperoxide- or D-galactosamineinduced toxicity in rat primary hepatocytes. Planta Med 2003; 69: 33-37. 